\title{
Anti-CEA Antibody
}

National Cancer Institute

\section{Source}

National Cancer Institute. Anti-CEA Antibody. NCI Thesaurus. Code C2456.

Any antibody against the tumor associated antigen carcinoembryonic antigen (CEA;

CEACAM5), with potential antineoplastic activity. The CEA antigen is overexpressed in certain types of cancer cells. 